Fall 2018

\title{
Dynamic Firm Location Network Model with Anticipatory Scenarios for the Northeast Ohio Region
}

\author{
Sanda Kaufman \\ Cleveland State University, s.kaufman@csuohio.edu \\ Miron Kaufman \\ Cleveland State University, m.kaufman@csuohio.edu \\ Mark Salling \\ Cleveland State University, m.salling@csuohio.edu
}

Follow this and additional works at: https://engagedscholarship.csuohio.edu/urban_facpub

Part of the Urban Studies and Planning Commons

How does access to this work benefit you? Let us know!

\section{Repository Citation}

Kaufman, Sanda; Kaufman, Miron; and Salling, Mark, "Dynamic Firm Location Network Model with Anticipatory Scenarios for the Northeast Ohio Region" (2018). All Maxine Goodman Levin School of Urban Affairs Publications. 01231581.

https://engagedscholarship.csuohio.edu/urban_facpub/1581

This Article is brought to you for free and open access by the Maxine Goodman Levin School of Urban Affairs at EngagedScholarship@CSU. It has been accepted for inclusion in All Maxine Goodman Levin School of Urban Affairs Publications by an authorized administrator of EngagedScholarship@CSU. For more information, please contact library.es@csuohio.edu. 


\title{
Dynamic Firm Location Network Model with Anticipatory Scenarios for the Northeast Ohio Region
}

\author{
Dr. Sanda Kaufman, Professor
}

Department of Urban Studies, Levin College of Urban Affairs, Cleveland State University

Corresponding author: s.kaufman@csuohio.edu

Dr. Miron Kaufman, Professor

Department of Physics, Cleveland State University

Dr. Mark Salling, Urban Fellow

Levin College of Urban Affairs, Cleveland State University

\begin{abstract}
Public policy and planning decisions require glimpses into the future, to assess how the social-ecological systems we plan for might evolve with or without policy intervention. To do so, one approach gaining currency is using anticipatory tools rather than predictions. Anticipation entails generating a range of possible systems futures (scenarios), instead of attempting to predict the one that will prevail. We use here a scenario-generating model, to anticipate where in a region businesses are likely to locate in time. Using data for Northeast Ohio, including the Cleveland-Akron-LorainElyria, Ohio Combined Statistical Area, we estimate the model parameters. We evaluate its prediction accuracy against 2001-2015 regional data. To illustrate how policymakers could use the model, we generate three scenarios to explore what might happen to the spatial configuration of businesses if policies were implemented to attract businesses at specific locations or discourage them from locating in parts of the region.
\end{abstract}

Keywords: regional firm location, regional urban systems, spatial dynamic location model, anticipatory public policy scenarios 


\section{Modelo de red de ubicación dinámica de la empresa con escenarios anticipatorios para la región noreste de Ohio}

\section{RESUMEN}

Las políticas públicas y las decisiones de planificación requieren vislumbres del futuro, para evaluar cómo los sistemas socioecológicos que planificamos podrían evolucionar con o sin intervención de políticas. Para hacerlo, un enfoque que gana dinero está utilizando herramientas de anticipación en lugar de predicciones. La anticipación implica generar un rango de posibles futuros de sistemas (escenarios), en lugar de intentar predecir el que prevalecerá. Utilizamos aquí un modelo generador de escenarios para anticipar dónde es probable que las empresas ubicadas en una región lleguen a tiempo. Utilizando datos para el noreste de Ohio, incluido el área estadística combinada Cleveland-Akron-Lorain-Elyria, Ohio, estimamos los parámetros del modelo. Evaluamos su exactitud de predicción contra datos regionales 2001-2015. Para ilustrar cómo los legisladores podrían usar el modelo, generamos tres escenarios para explorar qué podría pasar con la configuración espacial de las empresas si se implementaran políticas para atraer negocios en ubicaciones específicas o para evitar que se establezcan en partes de la región.

Palabras clave: ubicación de empresas regionales, sistemas urbanos regionales, modelo de ubicación dinámica espacial, escenarios de política pública anticipatoria

\section{动态公司位置网络模型：俄亥 俄州东南部的预期场景}

摘要

公共政策和计划决策需要将未来考虑在内, 进而评估被计划 的社会生态系统是否可能会与政策干预一同发展。为此, 一 种通用的途径则是使用预期工具, 而不是预测。预期是指产 
生一系列可能的系统未来（即不同场景），而不是试图预测 哪种场景占主导地位。笔者使用一种 “场景产生” 模型, 用 于预测区域中的哪个部分能使公司及时选址建立一事成为 可能。通过使用俄亥俄州东北部的数据, 包括克里夫兰一阿 克伦-洛雷恩-伊利里亚（俄亥俄州联合统计区），笔者预测 了模型参数。笔者以2001-2015年间的区域数据作为参考, 对 预测准确性进行了评价。为阐述政策制定者如何能使用该模 型，笔者提出了三种场景，用于探索公司空间配置将会发生 什么一一如果政策的实行是用于吸引公司在特定地区选址成 立, 或是不支持公司在某地成立。

关键词：区域公司位置, 区域城市系统, 空间动态位置模 型，预期公共政策场景

\section{Anticipatory Scenarios and Robust Decisions}

$\mathrm{P}$ olicy and planning decisions, even if implemented in the short term, require glimpses into the future policymakers are attempting to fashion and affect. Such decisions are informed by assessed needs, factual (measurable) and experiential data (the information base), and by goals and objectives of the stakeholders. The necessary knowledge of future states (and their likelihoods) of the systems subject to policies is usually obtained through forecasting. The longer the policy horizon, the more prone to error forecasts become. This is more so in the case of social-ecological systems, which tend to return low and slow feedback. Therefore, policymakers can either operate in the more predictable very short term and then wait for the consequences to materialize in time, hoping for the best, or rely on the more error-prone predictions for longer horizons.

Added to the decrease in time of prediction precision under any circumstances, the complexity and dynamic nature of social-ecological systems and their interrelatedness impede conjecturing efforts about effects of intervention and lack thereof. The traditional prediction toolbox for testing consequences of interventions is dominated by approaches that assume caeteris paribus ("all-else-being-equal") conditions. Arguably, in few to no situations can all else be reasonably assumed stationary; rather, all aspects of the affected social-ecological systems are usually in flux. Therefore, predicted changes in the one aspect subject to intervention are unlikely to inform policy decisions accurately, and may miss undesirable side-effects.

Two key components of a new policy's information base are necessarily 
connected to the uncertain future. First, decision makers need to guess how the social-ecological systems in their focus will evolve in the absence of intervention; after all, with luck they might be moving on their own in desirable fashion. Second, decision makers also need to guess how these complex, interacting systems in constant flux might react to various proposed interventions to steer them away from their current tendencies, should they be undesirable, and about other possible beneficial or unintended consequences of intervention.

The first kind of guess, about how a system might evolve in the absence of interventions, is necessary in order to assess needs and inform arguments for change. Predicting how the status quo will evolve is hampered by the fact that, even if we don't actively intervene in a system, rarely will it stay the course for longer than the very short run. Although the best prediction of where a system might be next year is often its state in the current in year, various events, sudden or slow-unfolding shocks, and numerous decisions will take the system off its current path in ways difficult to predict with any precision beyond about three to five years. ${ }^{1}$ This horizon is too short for social-ecological systems and their evolution in time. Beyond it, the range of predicted possible outcomes becomes so wide as to amount to no information for decision making.

The second kind of guess necessary in order to formulate policies entails figuring out how systems in which we intervene will respond to our decisions in time. Because they are complex, systems are unlikely to yield precisely the results we seek, and only those. The systems for which we plan tend to return feedback slowly, because the consequences of our decisions may take time to manifest themselves (e.g., Dörner, 1996). Consequently, it is often difficult to unequivocally derive causal links between specific decisions and outcomes. The history of public policy is replete with examples of failure to attain the objectives sought, or of unexpected and undesirable side-effects that in time render the decisions unwise in hindsight, despite the best of intentions driving them. What are policymakers to do?

Multivariate statistical regression modeling, which attempts to employ causal factors, has been a staple in the policy field for predicting futures. However, predictions of future states of complex systems for decision purposes may fail for several interrelated reasons when based on such regression approaches. The theory behind model specifications is often either weak or nonexistent-challenged as it is by complexity - and therefore the number and choice of variables can be idiosyncratic and driven by data availability. The horizon of such predictions is severely limited, as errors quickly accumulate and propagate yielding wide confidence intervals. Perhaps, the most important cause of failure is that these models do

1 Dempster and Wildavsky (1979) offered arguments to this effect in the context of budgetary processes, which are generalizable to the context of social ecological systems. 
not capture emergent phenomena resulting from numerous interactive decisions that yield their own outcomes (Bonabeau, 2002). Such emergent phenomena in the policy and economic development fields include traffic (Klügl \& Bazzan, 2012) and road congestion (Manley \& Cheng, 2010), the performance of creative firms (Kourtit, Arribas-Bel, \& Nijkamp, 2012), development under planning restrictions (Broitman \& Czamanski, 2012), networked communications (Beaverstock, Doel, Hubbard, \& Taylor, 2002), and consequences of climate change (Kriegler et al., 2012). Barthelemy (2016) offers a comprehensive survey of models that have been used to capture urban structure and change dynamics.

Although the poor performance of predictions is enough to drive us into inaction, this is clearly not an option. We make policies to improve the status quo and obtain a better outcome in the future than we expect with no action. Policymakers have used a variety of strategies and techniques to increase the likelihood of good outcomes and diminish the unwanted side-effects of decisions. Developing and applying best practices, using pilot projects to explore the effectiveness of policies before applying them on larger scales, and increasingly sophisticated prediction methods are all helpful. One approach gaining currency is the use of anticipatory tools, replacing reliance on predictions. For example, in the context of governance, Quay (2010) argued for its use in responding to climate change;
Fuerth (2009) offered similar arguments for addressing poverty. Fuerth and Faber (2012) broadened the scope and range of applicability of anticipation to other government activities. Bonabeau (2002) offered examples in several other contexts, where agentbased modeling replaced prediction. Anticipation entails generating through a variety of means a range of possible systems futures, or scenarios, instead of attempting to predict the one that will prevail. While not fail-safe, this approach has several advantages.

Scenarios help policymakers and planners make robust decisions. A decision that aims to address in the best possible way a specific predicted future is very likely to be suboptimal or even undesirable if a different future materializes. It is thus perilously sensitive: it only works well if we guess the future correctly. However, the likelihood that a specific point- or narrow-range prediction for a complex system will materialize is very small indeed. Considering a broad range of possible futures through scenarios allows us to pit our decisions against the range. A robust decision is one that remains wise for a large segment of this range. Moreover, since the actual future may still fall outside the range we choose to explore (including the occurrence of "black swans,"2 Taleb, 2007), we may be able to make provisions that lessen the negative effects under such circumstances (Lempert, Groves, Popper, \& Bankes, 2006; Groves \& Lempert, 2007). Since policymaking is a joint decision process, seeking ro-

2 Taleb (2007) coined the term "black swan" for events so highly improbable that we are unable to imagine them until they happen. Therefore, we fail to predict them. 
bust decisions affords more space for accommodating different perspectives than processes chasing optimal decisions that are sensitive to any modification. Scenarios can also be useful for communicating with stakeholders and involving them in policy decisions.

In what follows, we show how a parsimonious dynamic model (Kumar, Bowen, \& Kaufman, 2007, hereafter KBK) for anticipating the location of businesses in a regional space over time can be used to construct scenarios of consequences of various policy initiatives to encourage or to discourage businesses from settling in specific areas of a region, for development or conservation purposes. We begin by describing our approach to the validation of the KBK model and the data for the Northeast Oho region to which we applied it. Then, we discuss results of three policy scenarios constructed using the model. We conclude with some suggestions for how the model can be used to plan for the region studied and how it can be refined.

\section{Validating and Using the KBK Anticipatory Model}

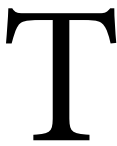
The KBK model has been used to describe how enterprises distributed themselves, in the absence of policy intervention ${ }^{3}$ in the matter, across Northeast Ohio between 1989 and 2001 (Kumar et al., 2007), and in a subset of it-Cuyahoga County (Kaufman \& Kaufman, 2015). We propose that with this model policymakers can explore, by means of scenarios, what might happen if specific policies were implemented to attract businesses at some locations or to discourage them from locating in other parts of the region.

The Northeast Ohio region is considered a legacy region, containing several legacy cities. The legacy status refers to "older, industrial urban areas that have experienced significant population and job loss, resulting in high residential vacancy and diminished service capacity and resources" (The Legacy Cities Partnership). Legacy cities and regions thrived during the industrial era in the 1950s and thereafter lost both population and parts of their economic base which relied heavily on the steel and car industries. For example, Cleveland's population in the 1950 Census was close to 915,000 , but by 2010 Census it had dropped to less than 400,000 . During this period, Cuyahoga County within which Cleveland is located lost population at a much lower rate: from 1.4 million in 1950 to 1.3 million in 2010. This pattern suggests that a considerable portion of Cleveland's loss was the county's gain, as residents and businesses relocated in the regional space.

To construct and use the scenarios with some confidence that they can represent business location choices a number of years after a policy has been implemented, it is necessary to evaluate first the model's performance. We used 1989 and 1991 data (the same as in $\mathrm{KBK}$ ) to estimate the four model parameters to be described shortly. We asked:

3 This does not mean that non-policy driven changes did not occur in the region during this time. 
1. How well does the model predict changes in the geographic distribution of firms in the region over time? Moreover, is the model's predictive performance sustained over this time period or does it decline rapidly? We compared actual and predicted business locations for the biennium years 2001-2015 to examine how stable the parameters are in time and what a reasonable prediction range is for this model, ${ }^{4}$ given that errors can be expected to grow in time with any model.

2. Is this model sensitive to shocks such as the 2008 economic downturn? This event occurred about midway between the years covered by the 2001-2015 data set. If so, is the effect immediate or does it have a lag? Can the model inform us about the lag to be expected between policy implementation and effects?

Answers to these two questions can indicate the extent to which the model can be used as a scenario-generating tool, and the time horizon over which it can be expected to return relatively reliable results, with tolerable errors (the differences between actual and predicted values, which increase in time for any model).

3. Given satisfactory performance in terms of the errors in the last year of data (2015), what future distributions of firms are likely given significant policy interventions?
To answer the third question, we designed and tested three scenarios corresponding to long-held regional goals-focused development of "legacy" cities, and conservation of undeveloped land with ecological value. We compared our scenario results to the model predictions in the absence of the interventions we proposed (also called "do-nothing"), which can also be considered a scenario, since it is very likely that during 2001-2015 and in the future interventions occur, whether through policies and regulations or economic activity.

We describe next in some detail the KBK model that we used to generate scenarios of emergent outcomes of firm location choices in a regional space, which we applied to data from the Northeast Ohio metropolitan region.

\section{The Model and the Data}

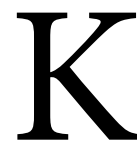
rugman (1996) proposed a dynamic rule for describing how new urban spatial configurations-specifically, in terms of business location-emerge from a current spatial configuration through interactions among the host localities in a region. This model attempted to explain the emergence of employment centers in the regional space as a result of the self-organization of a complex system. The KBK model is a discretized version of Krugman's model. According to the rule driving this model, any location is assumed to exert on firms an agglomerating force of attraction, and a disper-

4 By "reasonable range," we mean the time period during which we can use the model without fearing that prediction errors become so large that the prediction is no better than a guess. 
sion force that repels the firms. For any given location $\mathrm{x}$ in a region, the forces it exerts on firms, and therefore the extent to which it can attract them, depend on

$$
P_{t, x}=\sum_{y} q_{x, y} n_{t, y}
$$

where $n_{t, y}$ is the fraction of the total the spatial sum of the densities $n_{t, x}$ for number of businesses in a region found the region at any time $t$ equals unity. at location $y$, at time t. Consequently,

$$
\sum_{x} n_{t, x}=1
$$

In Equation (1), $q_{x, y}$ is the matrix of interactions between locations $\mathrm{x}$ and $\mathrm{y}$ :

$$
q_{x, y}=A \exp \left(-\frac{|x-y|}{D_{a}}\right)-B \exp \left(-\frac{|x-y|}{D_{b}}\right)
$$

where $|x-y|$ is the distance between any two locations $\mathrm{x}$ and $\mathrm{y} ; \mathrm{A}$ is the strength of the agglomeration force and $\mathrm{B}$ is the strength of the dispersion force; $D_{a}$ and $D_{b}$ represent the ranges of these interac-

$$
\bar{P}_{t}=\sum_{x} \sum_{y} q_{x, y} n_{t, x} n_{t, y}
$$

According to Krugman, businesses gradually move toward attractive locations, with above-average market potential $P_{t, x}>\bar{P}_{t}$, and move away

$$
\frac{n_{t+\Delta t, x}-n_{t, x}}{\Delta t}=\left(P_{t, x}-\bar{P}_{t}\right) n_{t, x}
$$

where $\Delta \mathrm{t}$ is the time interval. At any time $t$, the model preserves the spatial sum of the densities $n_{t, x}$ (Equation 2).

In order to estimate the four parameters $A, B, D_{a}$ and $D_{b}$, this model requires data about the number and location of firms in a regional space in two consecutive time periods. Then: tions. A, B, $D_{a}$ and $D_{b}$ are the four model parameters to be estimated from the data. The spatial average of the market potential at a specific time $t$-as defined in Equation (1) - is

from locations with below-average market potential $P_{t, x}<\bar{P}_{t}$. In the KBK implementation of Krugman's model, the dynamic equation is

- The actual number of firms in each locality of the region in the first time period is taken as the initial distribution of firms in the regional space;

- Equation (5) of the model is run with these initial data and a set of 
trial parameter values, to find the distribution of firms for the next period. The actual and model values of the Shannon information entropy are computed for this

$$
S=-\sum_{j} p_{j} \ln \left(p_{j}\right)
$$

where $p_{j}$ is the relative frequency of outcome $j$. second period. The Shannon entropy, which quantifies the system's degree of homogeneity (Shannon \& Weaver, 1998), is:
- An iterative search is conducted to identify the parameter values that yield the smallest difference between simulated and actual entropies for the second time period.

- After these "best" parameter values are thus obtained (in the sense that the difference between real and predicted entropies is the smallest) the proportion of firms at each location in the region is predicted for other time periods using the four parameters (Equation 5).

KBK applied the model and prediction procedure to the ClevelandAkron PMSA (192 municipalities) and data about firms' location in the years 1989-2001. This data set was derived from the Quarterly Census of Employment \& Wage (QCEW) data, with biennial information on $98 \%$ of the total employment and wages in the state of Ohio. This region includes the declining legacy cities Cleveland, Akron, Lorain, and Mentor.

KBK used consecutive data years 1989 and 1991 to estimate the parameters: $\mathrm{A}=1, \mathrm{~B}=0.818, \mathrm{D}_{\mathrm{a}}=0.909$, and $\mathrm{D}_{\mathrm{b}}$ $=0.273$. Then they predicted each mu- nicipality's share of firms for the following biennia 1993, 1995, 1997, 1999, and 2001 and compared them to the actual data. The model performed very well, as judged by deviations from the real data in 2001 ranging between $-.4 \%$ and $+.4 \%$ and for 6 municipalities between $-.8 \%$ and $.8 \%$. Running the model with data on consumer firms only yielded even better results, with 2001 prediction errors of maximum $\pm .5 \%$ for all but 2 municipalities.

Drawing on the same QCEW data source, we use the KBK model and parameters to generate scenarios with biennial data from 2001 to 2015 for the Northeast Ohio region, comprising the 2007 Cleveland-Akron-Elyria, Ohio Combined Statistical Area (CSA) and the Akron, Ohio Metropolitan Statistical Area (referred to here as CALE) which is the same region as in $\mathrm{KBK}$ (Figure 1).

However, in 2001, an improvement in the QCEW data precision introduced a relatively slight discontinuity among the two data sets-1989-2001 and 2001-2015..$^{5}$ We first predicted the 2001-2015 location of firms in the CALE CSA for 261 municipalities.

52001 is an overlap year, for which data were available both in the old and new data sets. 


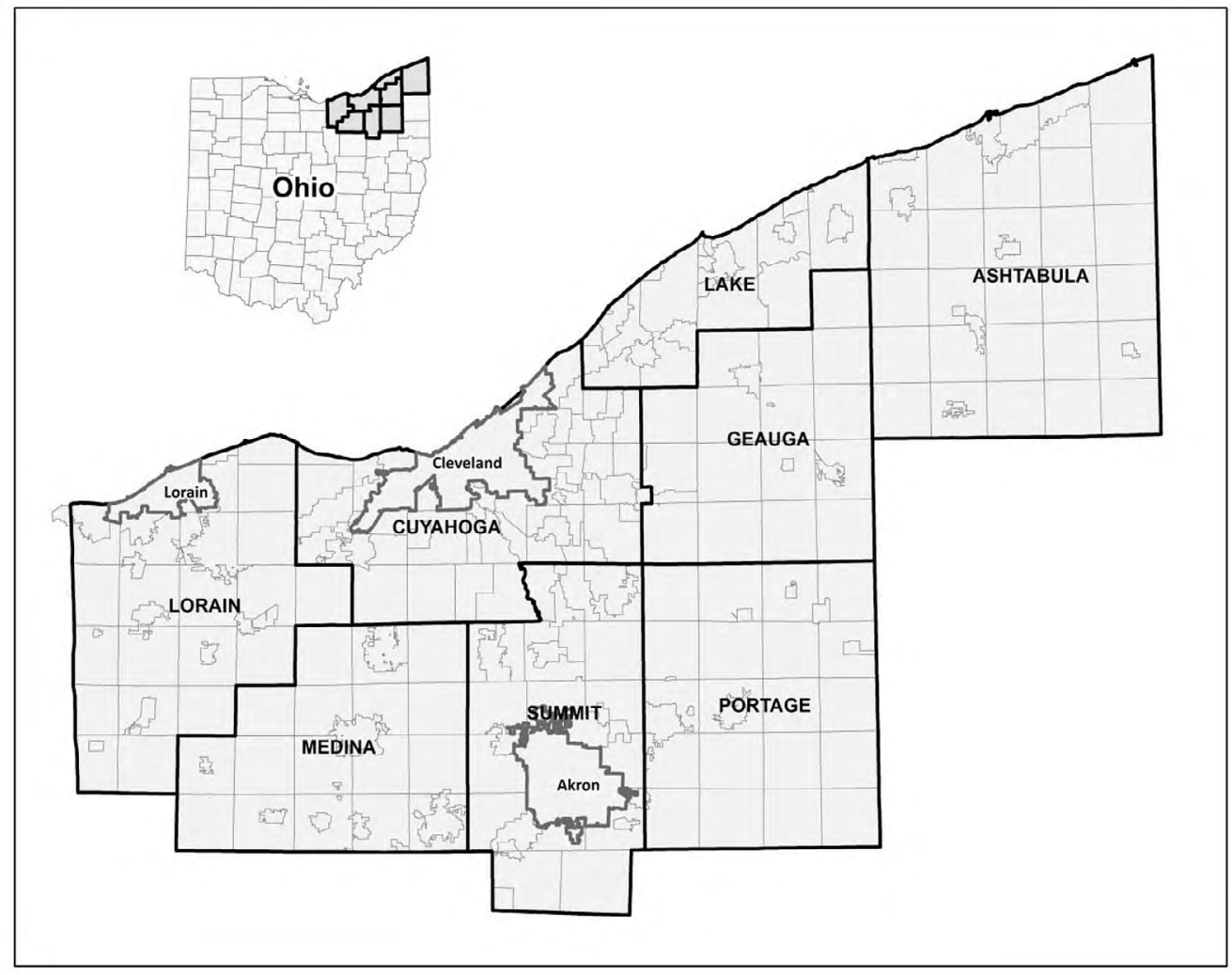

Figure 1. Cleveland-Akron-Lorain-Elyria, Ohio CSA.

The discontinuity in the data quality prompted us to focus on the 20012015 , both for model validation and for generating policy scenarios discussed below.

\section{Results of the KBK Model Validation for Northeast Ohio}

Using Equation 5 and the KBK parameters, we predicted the share of the total number of CALE firms at each of the 261 locations for each data year from 2001 to 2015 (12-26 years beyond the KBK data set from which the parameters were estimated). ${ }^{6}$ We analyzed re- sults to answer our Question 1 regarding the model's predictive performance in time, by comparing predictions and actual numbers for 2001-2015. A strong outcome with a quarter century-old parameters would enhance our confidence in any anticipatory scenarios generated using this model to explore consequences of proposed policy decisions that can affect spatial firm location dynamics in this region.

The predictions and actual values of firm shares in 2015 (the year in which we would expect the largest accumulated errors) are mapped in Figure 2. Their differences are displayed in

6 As we note in the concluding comments of the paper, the model treats the region as a closed system and distributes relative changes within that system. 
Figure 3. The largest difference between actual and estimated proportion of establishments is .01. The four legacy cities in the region tended to slightly over perform in the model, suggesting that in reality they attract a smaller share of businesses than their market potential indicates. Model underperformers with respect to the actual data (by only up to .002) were located mostly in the Cuyahoga County surrounding Cleveland, not coincidentally a pattern that

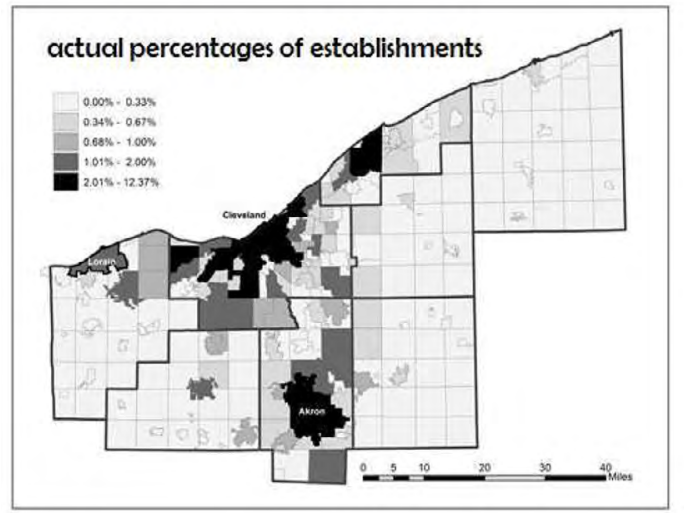

also reflects residential sprawl. These details are shown in Figure 4 for the three large legacy cities in the study region. Since the model captures spatial interactions among the market potential values of the localities considered, these results suggest that economic performance of these cities could be better, were it not for factors external to the model, such as social dynamics and various policy decisions.

Figure 2. Actual and predicted percent distribution of establishments in 2015.

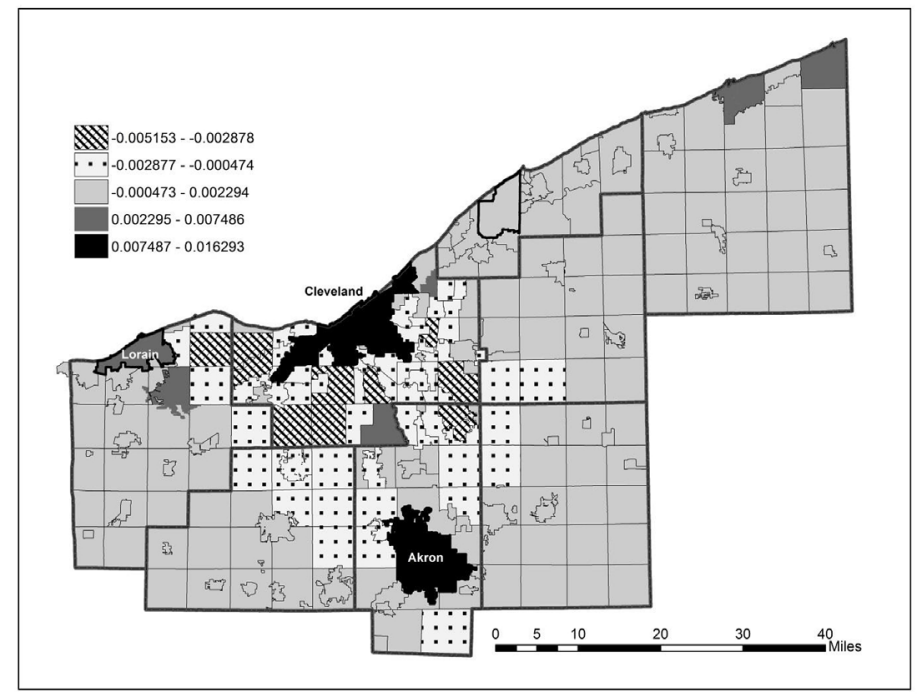

Figure 3. Error: Difference between model and actual percent distribution of establishments in 2015. 

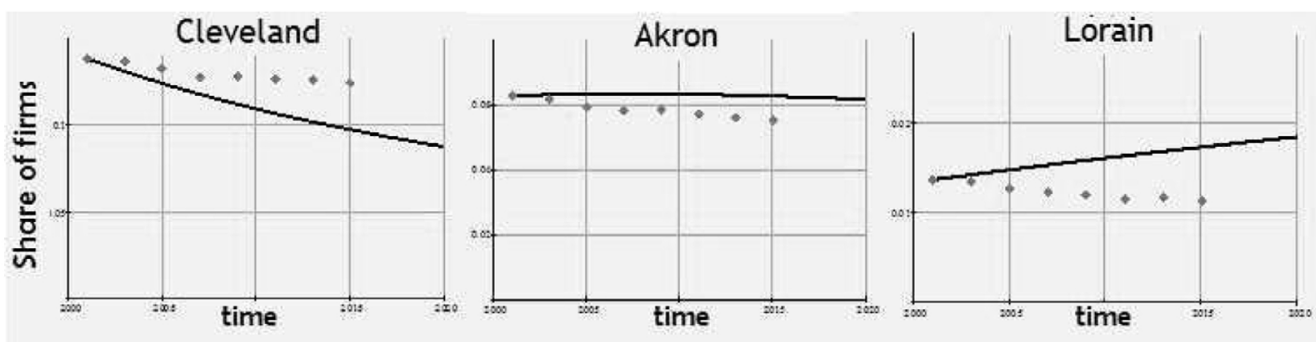

actual $\diamond \diamond \diamond$

model

Figure 4. Place-specific results: Predicted versus actual percentages, for legacy cities: Cleveland, Akron and Lorain.

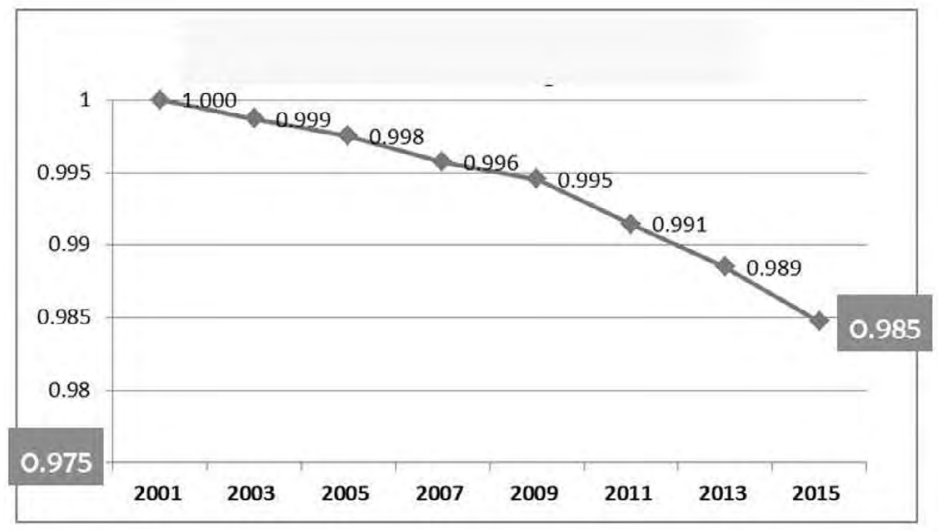

Figure 5. Correlation between actual and predicted shares of the total number of CALE firms at each location between 2001 and 2015.

A global measure of model accuracy is the Pearson's correlation in time between predictions and actual values (Figure 5). The "worst" correlation value, for 2015 using 25-year-old (19891991) parameter estimates, is $.985 .^{7}$ Thus, we conclude that it is reasonable to use our 4-parameter model for anticipatory purposes for the Northeast Ohio region.

Our results also answer Question 2 , regarding the robustness of our mod- el to shocks. The longer the prediction time period, the more we can expect changes in the national or local economy, or policies affecting firm location. For example, our prediction period contains the 2008 economic downturn, from which we might expect effects both in number and location/relocation of firms. However, we have seen no related discontinuity in our predictions. Based on the 2009 correlation value of .995 and the monotonic slow

7 For each point (biennium), the number of pairs is 261 and the corresponding $p$ value is around 0.0000 . 
drop of correlation values, we conclude that the precision of our prediction for Northeast Ohio was unaffected at least for this specific event. We describe next how we addressed our Question 3, regarding the use of the model for policy purposes.

\section{Three Anticipatory Northeast Ohio Policy Scenarios}

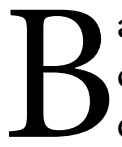
ased on the validation results, we concluded that the KBK model has good potential for asking "what if" questions to explore consequences in time of ways in which the location of establishments in the Northeast Ohio regional space could be altered for specific policy purposes. In this region, two objectives have been persistently proposed for several decades. They have both economic and environmental dimensions.

The first objective, derived from the goal of revitalizing the region after the drastic loss of population and manufacturing industries it experienced, has been to encourage a return to locations in the city centers for both residents and enterprises. The economic benefits include shoring up the cities' declining tax bases and providing employment to the less mobile segments of the population in a region that lacks a good public transportation network. The environmental benefit consists of discouraging and even reversing urban sprawl, which has encroached over the decades on valuable open space and fragmented ecosystems of the region, leading to loss of wetlands and wildlife habitat. The sprawl also imposes costs of extending infrastructure to a larger distance than is necessary to serve the current population. To attain the objective of return to the city centers, policies could offer incentives such as tax abatements for businesses, and public infrastructure investments that favor central city locations.

The second objective, not unrelated to the first, is chiefly environmental, with some potential economic side benefits. It is to increase conservation of open spaces in the region by discouraging establishments from locating in environmentally sensitive areas that would be degraded by the presence of intense human activity such as occurs both during construction and operation of new facilities. Secondary economic benefits include enhanced attractiveness of some natural areas to tourists. To attain this objective, policies may create disincentives such as costly remediation requirements, the obligation to recreate certain natural features such as wetlands at other locations, or outright interdiction to locate in certain areas such as riparian corridors. Such policies might enhance the effects of positive incentive to attract businesses to city centers through a forced scarcity effect.

One example combining both kinds of policies to alter business location in the regional space is the Ohio Balanced Growth (OBG) program, which is "a voluntary, incentive-based strategy to protect and restore Lake Erie, the Ohio River, and Ohio's wa- 
tersheds to assure long-term economic competitiveness, ecological health, and quality of life. The goal of the program is to link land use planning to the health of watersheds and major water bodies" (Ohio Balanced Growth Program). The OBG aims to protect water resources through land use decisions. Thus, it illustrates intervention policies that alter the configuration of regional spaces.

Since 2011, the state of Ohio in partnership with several agencies has implemented a policy for accomplishing both environmental and economic objectives. The voluntary OBG program consists of two key measures (described in its Strategy and its Best Local Land Use Practices): a request for all municipalities to designate their own priority development, conservation and agriculture areas; and a points scheme benefitting localities that develop priorities, facilitating the permitting of businesses that choose to locate in development areas and discouraging location in conservation areas. While the notion seems simple, its implementation may have run into difficulties. ${ }^{8}$

The OBG program relies on municipalities to make their own decisions regarding designation of development or conservation areas, almost independently of others in the region. Any coordination happens around specific ecosystems that straddle political boundaries, such as watersheds. However, business location decisions are in- terdependent and there is no method/ provision built into the program to assess the regional effects of these decisions. However, in time these kinds of decisions are apt to enhance or detract from a location's ability to attract and retain businesses-its market potential. These effects do not always occur where intended and sometimes surprise. The anticipatory scenarios we propose might be used to explore such effects, strengthen the positive ones, and avoid some unwanted side-effects.

Another example focused on the Northeast Ohio region is the Vibrant NEO 2040 planning framework (Vibrant NEO Full Report, 2014). It aimed to "create a more vibrant, resilient, and sustainable Northeast Ohio-a Northeast Ohio that is full of energy and enthusiasm, a good steward of its built and natural resources, and adaptable and responsive to change." Among other proposed actions to attain this goal, Vibrant NEO encouraged steering residential and commercial activities toward already-developed city cores, and protecting the region's still undeveloped land. This framework offers principles for arriving at siting decisions in the region, but cannot capture the effects of interdependencies among these decisions. Here too, an exploration of the dynamic evolution of the regional space under various scenarios could help refine and implement the framework.

8 The Balanced Growth Program (http://balancedgrowth.ohio.gov, last visited on June 10, 2018) has not posted any fact sheets or strategy updates beyond 2014 and did not list any events beyond 2016. Links such as "News" are no longer active. The site still offers access to information for those who would voluntarily engage in the practices it recommends, though it is unclear if state-provided incentives are still available for them. 
We describe here three scenarios consistent with both the OBG program and the Vibrant NEO 2040 framework, and compare them to the "do nothing" scenario (Figure 6). The first two scenarios illustrate what happens to the regional spatial configuration as a result of incentives to locate in city centers. The third scenario illustrates possible
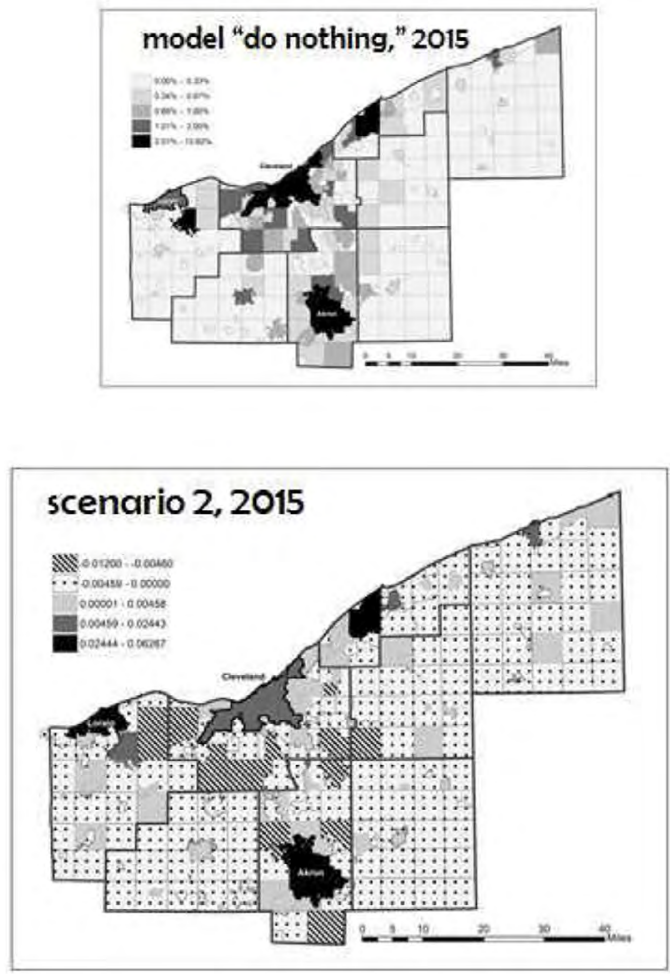

Figure 6. Scenarios 1, 2, and 3-2015 Results of Policy Changes in 2001, 2003,

2005, and 2007, Compared to the "Do Nothing" Scenario.

For all three scenarios, we asked:

- What is the resulting distribution of businesses in the regional space over time? For example, for the first two scenarios that boost some places in the region, is the regional effects of imposing disincentives to locate in conservation areas. Note that the maps show scenario results up to 2015; however, as is apparent in the examples for specific cities, the simulations ran to the 2040 time horizon. The graphs of proportions of establishments in the graphs for these examples have different scales.
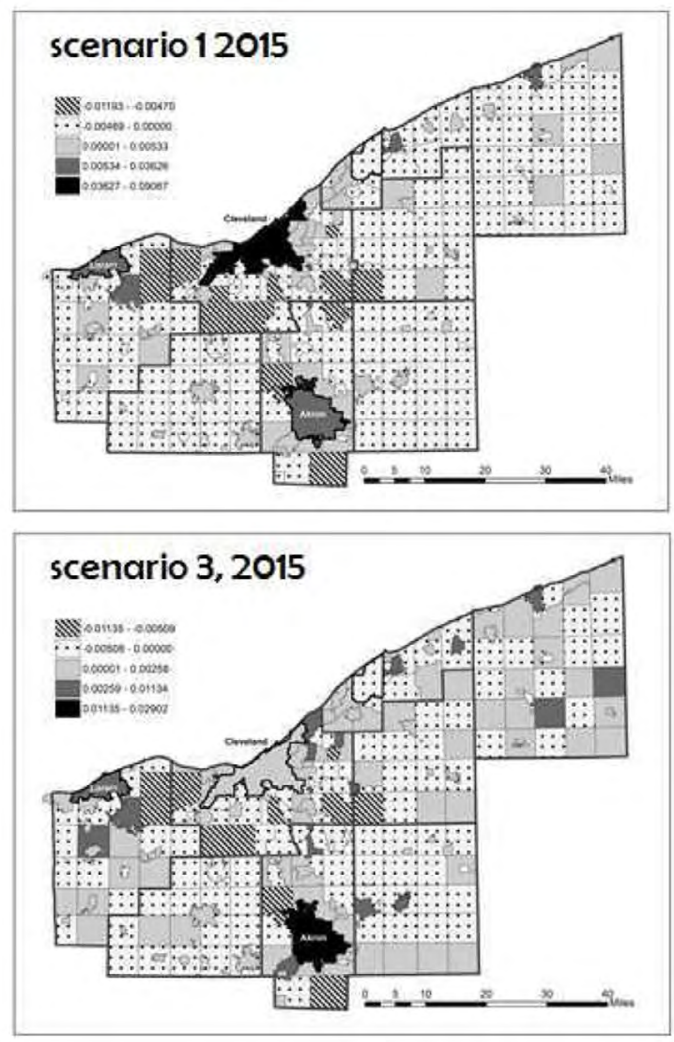
- Do the boosts and the conservation effort have a lasting effect? For instance, after boosts in four time periods are the respective cities able to continue growing even in the absence of the incentives? Are sidewins and losses also lasting?

\section{Scenario 1: Incentivize Businesses to Locate in Cleveland}

We created the first scenario by considering the possibility that for four time periods-2001 to 2007-the city government has successfully implemented a tax incentive of .04 (out of the regional total) in the proportion of establishments locating in Cleveland. In those biennia, this increase is accompanied by a corresponding decrease of .04 in proportions of establishments located everywhere else in the region. Note that in reality, such a policy may have aimed for more or less than the .04 increase. It would be difficult to design such a policy to obtain precisely a set proportion. We model here the result of the implemented policy, to assess the spatial pattern of the regional losses and enable decision makers to weigh pros and cons of the policy from a regional perspective.

In this scenario, aiming to benefit Cleveland by raising its relative market potential, some other cities (e.g., Akron and Lorain) also benefit, though less than Cleveland (see Figure 6 for a comparison of 2015 results between the intervention and the "do-nothing" scenario). On the other hand, some small places in the region "disappear" in the sense that their relative market poten- tial drops to a level where they no longer attract any establishments. Figure 7 shows several consequences in time of the Cleveland boost. First, compared to the "do-nothing" scenario Cleveland performs better across the entire time period (through 2040). After the boost years, however, the effect slowly decays in time. Akron and Lorain, large legacy cities close to Cleveland, react positively, reaching sustained slightly higher levels of activity than without the boost, though with a lag. On the other hand, the small Boston Township exemplifies the small places in the region that quickly lose their attractiveness to businesses during the boost years, and do not recover.

\section{Scenario 2: Incentivize Businesses to Locate in the Region's Legacy Cities}

In the second scenario, we have tested the consequences of increasing for four time periods (2001-2007) the attractiveness for business location of the four legacy cities within the Northeast Ohio region: Cleveland, Akron, Lorain and Mentor (Figure 6). As in the first scenario, the increase of .01 in the proportion of businesses in each of these four cities meant that the proportion of businesses across the rest of the region dropped by .04 .

Figure 8 shows what happened over time to the four cities targeted for a boost, as well as to two other small places in the region that "paid the price," as it were, for the assistance received by the legacy cities. The four legacy cities consistently outperformed the "do-noth- 
Dynamic Firm Location Network Model with Anticipatory Scenarios for Northeast Ohio
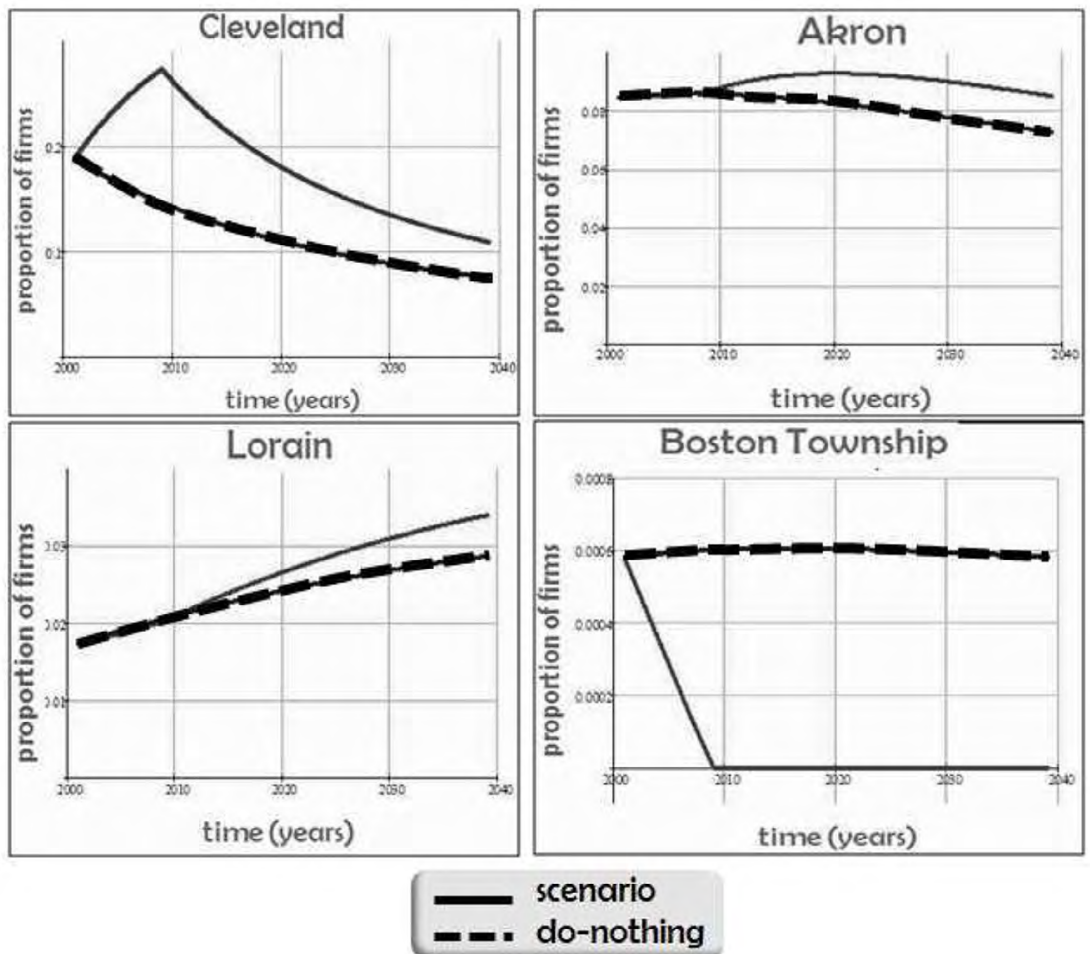

Figure 7. Scenario 1-Examples.
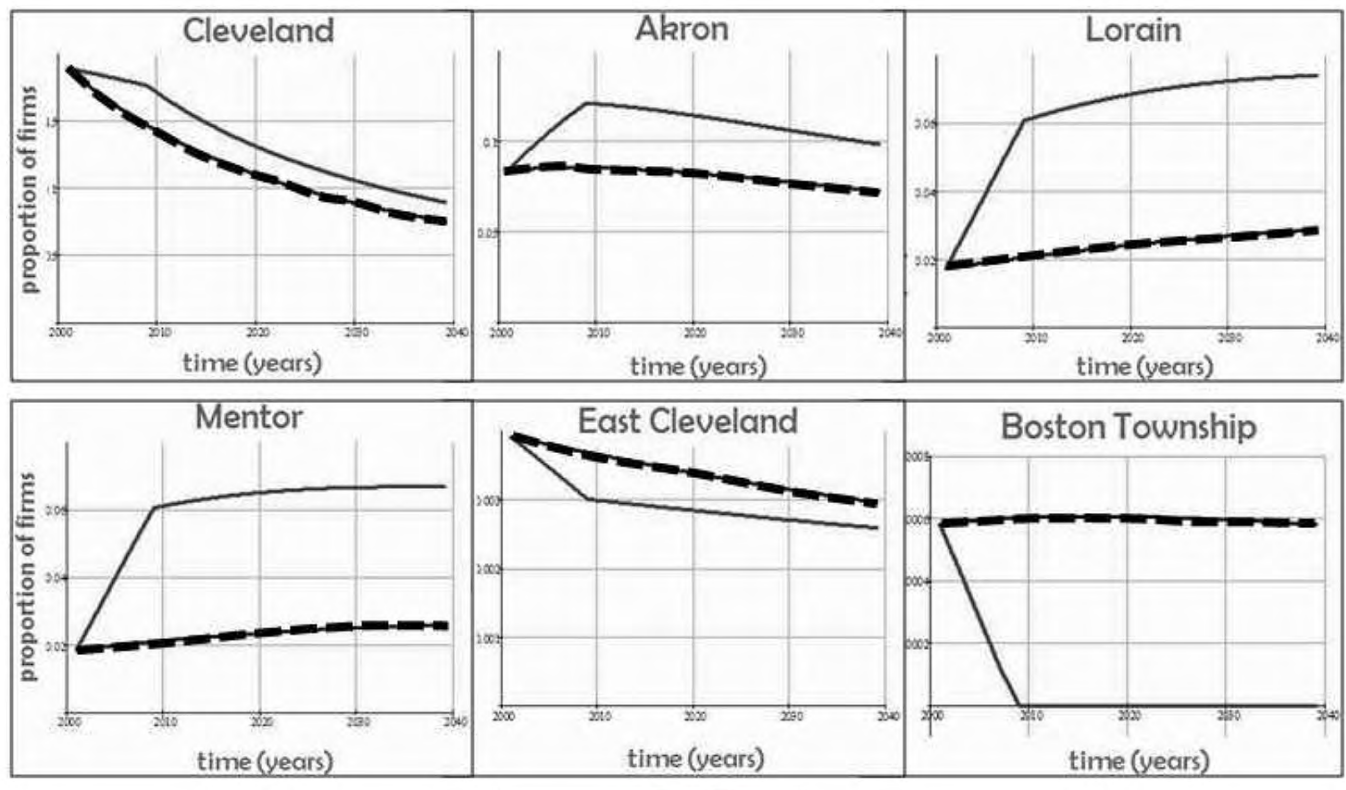

scenario

- n. do-nothing

Figure 8. Scenario 2-Examples. 
ing" scenario, but each in a different way. Cleveland benefitted less from the .01 boost and then reverted to decline, although at a slightly higher level, much as in Scenario 1. Akron, Lorain, and Mentor had a stronger response to their boosts and sustained them, though Akron's pattern resembles Cleveland's in that after the boost it resumes decline. Of the two small cities we illustrate, East Cleveland sees a stronger decline especially during the boost years, while Boston Township drops and never recovers any market potential, as in Scenario 1.

Since the model takes into account difficult-to-capture spatial interactions, scenarios 1 and 2 offer information that might not be available to policymakers otherwise. Specifically, enhancing Cleveland's (or all four legacy cities') market potential for a while through a policy intervention can have the desired result-but for a limited time, after which Cleveland's decline resumes. However, the cost of the temporary success is paid by small cities whose relative market potential is all but eliminated. These smaller places are unlikely to come back from the drastic decline inflicted by the policy. Our observation is neutral with respect to the policy: decision makers may view these results positively, in terms of the tradeoffs implied. However, we propose that such tradeoffs may not be apparent to the decision makers in the absence of anticipatory scenarios. The outcomes, especially if deemed undesirable, may surprise when they become irreversible.
Scenario 3: Discouraging Businesses from Locating in Close Proximity to the Cuyahoga Valley National Park

In the third scenario, we have capped the market potential of 14 municipalities adjacent to the Cuyahoga Valley National Park at their level in 2001 (Figure 6). The corridor surrounding the park and its river is ecologically sensitive to building activities that tend to disrupt wildlife habitat. Often, however, such scenic areas are also attractive for residential and commercial purposes. Therefore, conservation set-asides are tools to protect the land from being taken over by environmentally damaging land uses.

Figure 9 shows that Cleveland's market potential is unaffected by the conservation set-asides. Similarly, East Cleveland shows no change from the "do-nothing" scenario. Two other small townships-Cuyahoga Falls and Boston Township show a constant market share in time close to their respective "do-nothing" levels. Thus in the case of the Northeast Ohio region and the specific set-asides we have considered, it seems the cities' relative market potential is largely unaffected, which should make it politically easier to implement such a policy.

\section{Conclusions and New Directions}

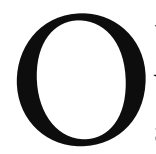
ur findings encourage us to develop the use of our model for anticipatory purposes. We have yet to find in the literature the level of 

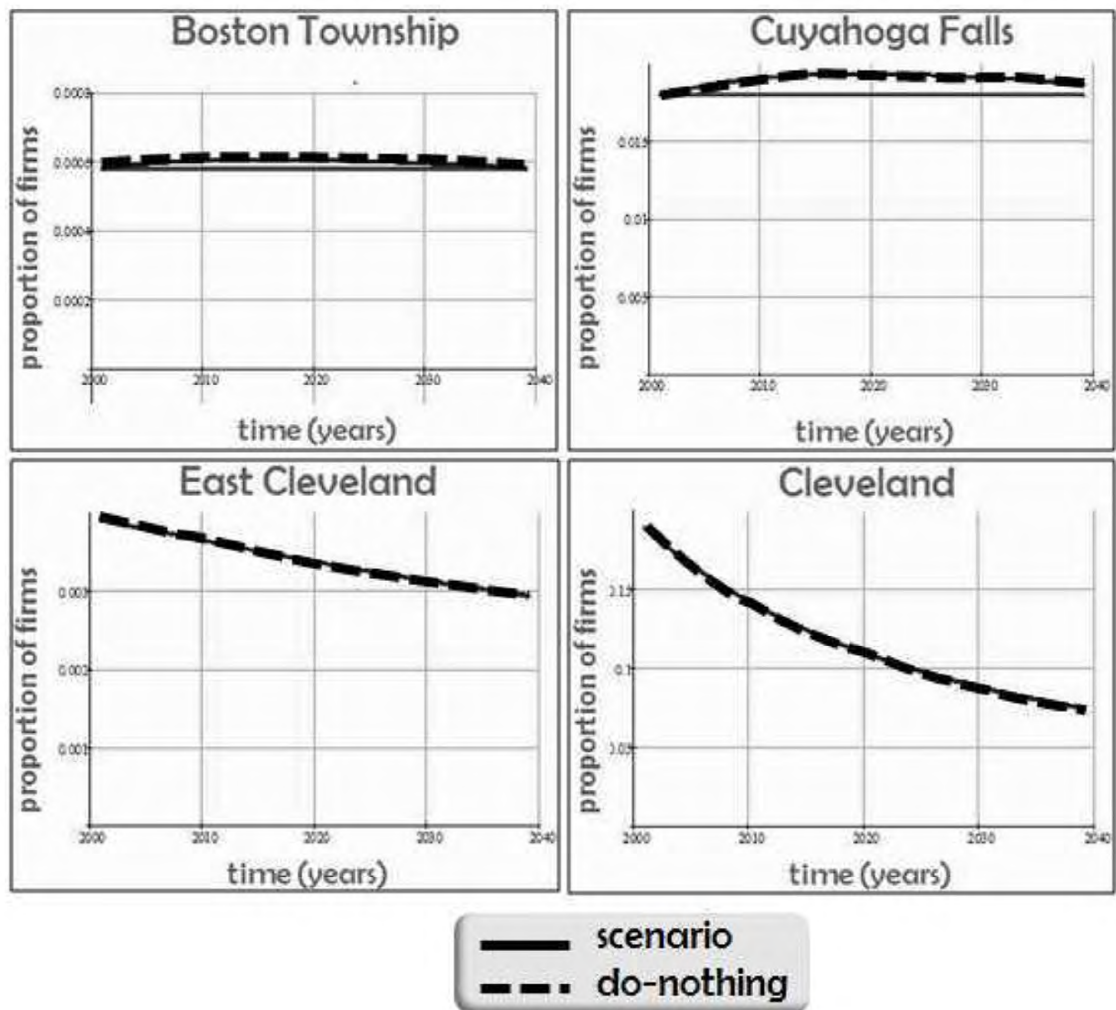

Figure 9. Scenario 3-Examples.

predictive performance (as reflected in the correlations over 15 years between predicted and actual values) especially with such parsimonious means. Moreover, the model is practical, in the sense that its only four parameters can be estimated from readily available data. We showed how this model could be used in anticipatory mode, to explore consequences in time of various policies that affect business location decisions in the regional space. We captured the spatial location effects a public policy intervention (such as tax incentives at specific locations) might have. We also explored effects of land conservation measures that remove certain areas from development. Beyond the illustrative scenarios discussed, the model can be used to test the same policy interventions at different levels, to explore whether some thresholds emerge beyond which results differ qualitatively and quantitatively. We can also derive ranges of policy impacts to promote robust decision making.

However, some caveats are in order. The strong long-range performance of the model from 2001 to 2015 using parameter estimates based on 1989 and 1991 data may be due in part to the legacy status of the CALE region we studied. Legacy regions are relatively stagnant or declining. This may account both for the model's strong predictive performance and for scenario results that show a lack of market potential 
consequences of a conservation policy on most municipalities. To test this conjecture, we need to use the model with data from a growing, more rapidly changing region (such as Dallas, Texas). Perhaps predictions would diverge from the actual outcomes more rapidly in such a region. It should be possible then to characterize and even categorize regions by a growth-related measure that limits the time period over which we can reasonably expect anticipatory scenarios based on our model to be reliable for answers to what-if questions.

The model in its current form treats the system as closed in each time period. The Northeast Ohio region's legacy status made this assumption not as unrealistic as it might be for other, more prosperous regions. After all, the model only forecasts relative growth and decline within a region. Places experiencing relative decline may in fact be growing in actual terms. Overall growth of the region is not factored in the model in its current state.

We plan to improve the model by allowing for in-flux or out-flux of firms, since each region is interconnected with other economic regions. Then we can identify locations in the regional space where strategic investments could attract firms, in order to achieve more quickly desired results. Furthermore, if the impedance of distance is measured with a transportation network the model's parameters may organize to reflect the relative importance of transportation technologies. Other measures of place size than the number of firms, such as population, may also be incorporated in the model, as might constraints and incentives beyond the public policy realm.

The anticipatory approach to exploring the future is not without drawbacks. We don't know what we don't know and are likely to fail to cover adequately the range of possible futures. Further, scenario generation is data-, skill-, and resource-intensive. Therefore, this approach is unlikely to be cost-effective for small-scale, shortrange policy decisions or for situations where the cost of being wrong is less than the cost of acquiring the necessary information to get it right. Selecting the variables that should be part of the scenarios and processing the resulting information to produce wise, robust decisions remains challenging. As models of reality, scenarios are incomplete and rely on assumptions over which there can be disagreement. Also, because they are technically complicated and often not sufficiently transparent, scenarios can come under the suspicion of being manipulative. However, the advantages of anticipation using scenarios outweigh the drawbacks in many contexts, such as the one presented here, where mistakes are very costly and their presence is not manifest for long time periods, after which adjustments may be difficult or impossible.

\section{References}

Barthelemy, M. (2016). The structure and dynamics of cities. Cambridge, United Kingdom: Cambridge University Press. 
Beaverstock, J. V., Doel, M. A., Hubbard, P. J., \& Taylor, P. J. (2002). Attending to the world: Competition, cooperation and connectivity in the World City network. Global Networks, 2(2), 111-132.

Bonabeau, E. (2002). Predicting the unpredictable. Harvard Business Review, 80(3),109-116, 134.

Broitman, D., \& Czamanski, D. (2012). Polycentric urban dynamics-Heterogeneous developers under certain planning restrictions. URISA, 24(1), 25-34.

Dörner, D. (1996). The logic of failure: Why things go wrong and what we can do to make them right. New York, NY: Metropolitan Books.

Fuerth, L. S. (2009). Foresight and anticipatory governance. Foresight, 11(4), 14-32.

Fuerth, L. S., \& Faber, E. M. (2012). Anticipatory governance practical upgrades: Equipping the executive branch to cope with increasing speed and complexity of major challenges. National Defense University Fort McNair DC, Institute for National Strategic Studies.

Groves, D., \& Lempert, R. (2007). A new analytic method for finding policy-relevant scenarios. Global Environmental Change, 17, 73-85.

Kaufman, M., \& Kaufman, S. (2015). Urban spatial economies on networks, NetSci2015, Zaragoza, Spain. Retrieved from https://ssrn.com/abstract $=2624174$.
Klügl, F., \& Bazzan A. (2012). Agentbased modeling and simulation. AI Magazine, 33, 3, 239-240.

Kourtit, K., Arribas-Bel, D., \& Nijkamp, P. (2012). High performers in complex spatial systems: A self-organizing mapping approach with reference to the Netherlands. Annals of Regional Science, 48, 501-527.

Kriegler, E., O'Neill, B. C., Hallegatte, S., Kram, T., Lempert, R. J., Moss, R. H., \& Wilbanks, T. (2012). The need for and use of socio-economic scenarios for climate change analysis: A new approach based on shared socio-economic pathways. Global Environmental Change, 22(4), 807-822.

Krugman, P. (1996). The self-organizing economy. Cambridge, MA: Blackwell.

Kumar, M., Bowen, W. M., \& Kaufman, M. (2007). Urban spatial pattern as self-organizing system: An empirical evaluation of firm location decisions in Cleveland-Akron PMSA, Ohio. The Annals of Regional Science, 41(2), 297314.

The legacy cities partnership. Retrieved from http://www.legacycities.org/.

Lempert, R. J., Groves, D. G., Popper, S. W., \& Bankes, S. C. (2006). A general, analytic method for generating robust strategies and narrative scenarios. Management Science, 52(4), 514-528.

Manley, E., \& Cheng, T. (2010). Understanding road congestion as an emer- 
gent property of traffic networks. In J. Shannon, C. E., \& Weaver, W. (1949). Baralt, N. Callaos, H. Chu, M. Savoie, \& The mathematical theory of communicaC. Zinn (Eds.), Proceedings of the Inter- tion. Champaign, IL: University of Illinational Multiconference on Complexity, nois Press.

Informatics and Cybernetics (IMCIC), 14th WMSCI, 109-114.

Taleb, N. N. (2007). The black swan: The impact of the highly improbable (Vol.

Ohio Balanced Growth Program. Retrieved from http://balancedgrowth. ohio.gov/. 2).New York, NY: Random House.

Quay, R. (2010). Anticipatory governance: A tool for climate change adaptation. Journal of the American Planning Association, 76(4), 496-511.

Vibrant NEO 2040. (2014). Full report. Retrieved from http://vibrantneo. org/vibrantneo-2040/vneo-2040-fullreport/. 